\title{
Vides i successos de quatre monjos de Sant Jeroni de Cotalba
}

\author{
Lives and events of four monks of Sant Jeroni de Cotalba
}

\author{
RuBÉN GALERA \\ sifanofa@hotmail.es \\ Universitat de València
}

Resum: El monestir de Sant Jeroni de Cotalba és una de les grans obres que va dur a terme el duc de Gandia, Alfons el Vell, a les darreries del segle xiv. Encara que el van fundar dotze monjos portats de la Plana de Xàbia, paulatinament van engrossir el nombre de religiosos que podia albergar, fins arribar-ne a quaranta. Un d'aquells monjos, que era arxiver, tenia cura de deixar per escrit les efemèrides més memorables dels avatars del monestir i dels seus religiosos. Amb el temps, això serví perquè els historiadors de l'Orde, com ara José Sigüenza, demanaren a cada monestir les dades més rellevants de la fundació i dels benefactors, però sobretot de les vides exemplars dels monjos. Per sort, el pare Francesc del Castillo, arquer i arxiver de Cotalba a la meitat del segle xviii, tingué la informació suficient per escriure la seua Historia del Real Monasterio de Sant Jerónimo de Gandía o de Cotalva. L'objectiu d'aquest article és, per tant, donar a conèixer només les vides excepcionals dels monjos de Cotalba que, dins la vida monàstica, van presenciar fets d'ultratomba, sanaren malalts crònics amb la fe i predicaren durant setmanes amb molt poques hores de descans.

Paraules clau: Sant Jeroni de Cotalba, Francesc del Castillo, crònica, vides exemplars de monjos

\begin{abstract}
The monastery of Sant Jeroni de Cotalba is one of the great works that the duke of Gandia, Alfons el Vell, carried out in the xiv century. Although it was founded by twelve monks brought from the Plana de Xàbia, gradually they increased the number of religious that it could host, in order to arrive at forty. One of those monks, who was an archivist, took care of leaving in writing most memorable ephemerides of the vicissitudes of the monastery and of their monks. Over time, that served for the historians of the Order, as José Sigüenza, to require every monastery the most relevant data of the foundation and the benefactors, but above all the exemplary lives of the monks. Luckily, Francesc del Castillo, accoutant and archivist of Cotalba in the middle of the 18th century, had enough information to write his Historia del Real Monasterio de Sant Jerónimo de Gandia o de Cotalva. The objective of this article is so to make known only the exceptional lives of the monks of Cotalba who, within the monastic life, they witnessed beyond the grave events, healed the chronic ill by faith and preached for weeks with very few hours of rest.
\end{abstract}

Keywords: Sant Jeroni de Cotalba, Francesc del Castillo, chronicle, exemplary lives of monks

\footnotetext{
* El present treball forma part del Projecte "Biografías marginales: violencia, sexo, género e identidad. Edición y análisis de las fuentes documentales valencianas de la época foral”, finançat pel Ministerio de Ciencia, Innovación y Universidades del Gobierno de España (PGC2018-097011-B-I00).
}

DATA PRESENTACIÓ: 17/09/2020 ACCEPTACIÓ: 16/10/2020 • PUBLICACIÓ: 10/12/2020 
La Historia del Real Monasterio de Sant Jeronimo de Gandía, o de Cotalva, també coneguda com la Crònica del pare Castillo, ${ }^{1}$ no ha sigut estudiada en conjunt i editada d'ençà que Roc Chabàs en va fer una còpia al 1880. ${ }^{2}$ Davant aquest -entre cometes- oblit, he registrat el títol de la meua tesi doctoral: per conèixer els avatars de l'autor de la crònica, Francesc del Castillo, per esbrinar les fonts que va consultar per a bastir un dels escrits historiogràfics més consultats de la Safor. Tanmateix, l'objectiu d'aquesta article és el d'extraure la relació de tres monjos exemplars i virtuosos que l'autor va deixar per escrit; i encara la d'un quart monjo que fa referència a una anècdota.

\section{Alfons el Vell i els jerònims}

Les primeres empremtes dels jerònims en terres valencianes les trobem al lloc que es coneix hui en dia la Plana de Xàbia. Vers els segles XIII i XIV s'havien instal lat en aquella contrada persones que buscaven un refugi i volien fugir de la vida mundanal del segle, per tal d'imitar la vida austera dels sants que idealitzaven. Cap al 1374, alguns d'aquells homes apartats del món, van presentar la proposta a Alfons el Vell, llavors senyor feudal de la Plana de Xàbia, de Dénia i de Gandia, entre altres llocs, de fundar un orde monàstic amb devoció a Sant Jerònim, un dels quatre grans pares de l'Església. ${ }^{3}$

Al poc temps d'aquella petició, Alfons el Vell els bastí un monestir de petites dimensions en la Plana, poc després que una delegació de tres monjos es desplaçara a Avinyó per a demanar al Papa que els atorgara una butlla fundacional. ${ }^{4}$ Malgrat la bona voluntat dels eremites de viure en la senzillesa, no tingueren en compte que la costa xabienca era un blanc fàcil per a la pirateria berberisca. Això tingué conseqüències: una ratzia de pirates de Bugia segrestà huit monjos i se'ls emportà a les seues terres. Sortosament, el duc de Gandia pagà el preu pel rescat d'aquests primers monjos. ${ }^{5}$

Perquè l'acció no es tornara a repetir, Alfons el Vell encarregà al seu home de confiança, Pere March, pare del poeta, que els bastira un nou monestir a l'interior de la Safor, a la Vall de Vernissa, en les terres d'un llogaret de musulmans valencians que es deia Cotalba. Deu anys després de la Butlla fundacional, cap al 1388, per fi pogueren organitzar-se com a institució religiosa i difondre la diàspora jerònima als altres indrets de la Corona d'Aragó, tot emparats per nobles rics, ducs i

1 Arxiu de la Catedral de València. Ms 368.

2 Possiblement, l'autor de la còpia de la crònica del pare Castillo va ser Roc Chabàs (1876). Ell és el primer historiador que la cita amb el nom orignal: Comentarios historiales y memorias breves del origen y progreso del Real Monasterio y comunidad de San Geróniom de Gandía, antes de Cotalva; després de dir que «todo lo preinserto es copia literal del manuscrito del P. Fr. Francisco Castillo».

3 ACV. Ms 368, cap. 8, p. 31-32.

4 ACV. Ms 368, cap. 6, p. 25.

5 ACV. Ms 368, cap. 9, p. 35-36.

SCRIPTA, Revista internacional de literatura i cultura medieval i moderna, núm. 16 / desembre 2020 / pp. 215-222 ISSN: 2340-4841 · doi:10.7203/SCRIPTA.16.19226 
reines, que els requerien per a fundar nous monestirs; és a saber: a la Murta, a Alzira; Miramar, a Mallorca; Vall d'Hebron i la Murtra, a Barcelona. A tots aquests monestirs es van desplaçar monjos experts de Cotalba per a instruir els futurs monjos professos i llecs. Per tant, es pot considerar que Cotalba és el monestir matriu de l'Orde dels jerònims de la Corona d'Aragó, com així se'l reconeix per a historiografia.

\section{La construcció de la memòria de les cròniques jerònimes}

La crònica que nosaltres estudiem en la nostra tesi no és cap altra cosa que el compendi de la informació en documents i cronicons que hi havia al monestir de Cotalba vers el 1757, any en què Francesc de Castillo reconstrueix la història del cenobi. El pare Castillo, llavors arxiver i arquer, escriu manta vegades que hi ha hagut un excepcional desinterés de posar per escrit les memòries dels religiosos i els fets més rellevants del monestirs xabienc i saforenc. Malgrat que hi havia llavors una crònica, que ell anomena El llibre de la fundació, les notes que arreplega no van més del segle XVI i es lamenta, ara i adés, que poc o gens se sap de les vides dels dotze monjos fundadors que es van traslladar des de la Plana de Xàbia a Cotalba. ${ }^{6}$ No obstant això, sí que recorre al llibre vell de la fundació, escrit pel pare Batiste de Salamanca, i a la documentació que s'havia mantingut en la biblioteca del monestir. Al cenobi consulta les cartes que els monjos s'enviaven per a ressenyar la vida dels frares més virtuosos ${ }^{7}$ i les històries de l'orde, entre les quals destaquen els llibres de José Sigüenza (1907-1909); i unes altres vegades consulta les butlles papals fundacionals, entre altres papers. Fora com fora, obté informació suficient per a escriure una història completa des del punt de vista religiós del monestir, però, tot siga dit, esbiaixada des del punt de vista politicosocial ja que no hi parla de fets cabdals com la Guerra de les Germanies, que va tindre lloc davant del monestir, en la Vall de Vernissa; i la Guerra de Successió, que l'obvia completament.

\section{Vida dels quatre monjos exemplars}

La vides dels monjos que ens interessa comunicar, que van viure entre el segle XV i XVI, presenciaren l'aparició de morts, com ara Vicent Martín, curaren malalts amb el simple fet de tenir fe, com ara Martí Pérez, foren virtusos perquè dormiren poc més d'una hora cada dia i durant quaranta dies, com el cas de Francesc Berenguer; i, en un altre cas, es salvaren de ser segrestats per una escaramussa de moros gràcies a les campanes, com és el cas de Francesc Berenguer.

6 ACV. Ms 368, cap. 3, p. 13: «Pero ya que fuese tanto el descuido que no escribiesen la antigüedad de los hermitaños».

7 ACV. Ms 368, cap. 34, p. 220.

SCRIPTA, Revista internacional de literatura i cultura medieval i moderna, núm. 16 / desembre 2020 / pp. 215-222 ISSN: 2340-4841 · doi:10.7203/SCRIPTA.16.19226 


\section{Rubén Galera. Vides i successos de quatre monjos de Sant Jeroni de Cotalba}

Veien-me la primera. Fra Vicent Martín, ${ }^{8}$ diu el pare Castillo, «se crió en esta casa siendo niño y pariente del padre prior que entonces era. Aquí aprendió la gramática y después le vistieron el hábito». Va viure uns 27 anys i va ser admirat per tota la comunitat. El seu confessor, Pere Coll, referí coses d'ell que disimulava en vida, com ara que va aconseguir l'esperit de profecia, perquè va saber el dia i l'hora de la seua mort i de la d'un company seu.

Entre algunes coses que refereix Francesc del Castillo, hem de destacar que era el «Día del Corpus por la tarde, y habían muerto algún tiempo antes doce o trece religiosos por la peste, y encendiendo fray Vicente las velas del altar mayor oyó una voz muy cerca de sí que le dijo: «sal al claustro y verás los religiosos que murieron de la peste», y salió luego y vio como los religiosos difuntos hiban en la procesión». Imagineu-vos el rebombori que degué causar aquella visió de monjos fantasmes, que s'arribà a pintar un quadre per a la Capella Major.

Un altre dels monjos que ressenya el cronista de Cotalba fa referència als miracles de fra Martí Pérez. ${ }^{9}$ Llec y profés, era «converso y había sido almugávar de moros, que entonces sonaba lo que ahora suena Miguelete». O siga, que passà de militar a monjo devotíssim. Diu el cronista que «a la fama de la santidad de este lego trajeron unos hombres de las montañas una moza contrahecha que tenía los dos brazos y manos secas». L'havia intentat curar un metge jueu de renom, sense haverhi tingut sort. Aquest metge, però, va voler acompanyar-la en la visita al prodigiós jerònim. Quan arribaren al monestir, esperaren que isquera fra Martí Pérez al costat de la torre de les campanes i «contáronle, pues, allí a fray Martín la causa de su venida [y] mostráronle la moza contrahecha de los dos brazos».

A partir d'ací el monjo comença a obrar el seu miracle amb un acte de fe en què la jove creu devotament en la religió i, de sobte, es produeix el miracle:

Miró el fraile a la moza y preguntó si era judío aquel que estaba allí con ellos. Respondieron que sí, y que era gran médico que había tenido en cura la moza mucho tiempo sin provecho alguno. Entonces el fraile le enderezó la plática al judío y díjole: «qué te parece judío, ¿puede sanar esta moza?

A tot això va respondre el jueu que era impossible per natualesa, perquè havia fet els possibles i no havia tingut sort a sanar la jove. Llavors:

8 ACV. Ms 368, cap. 34, p. 220: «Nuestro historiador, el padre Sigüenza, en la segunda parte, al folio 562, refiere algo de la vida de este siervo de Dios, fray Vicente Martín, y el Libro de fundación, al folio 28; y así, solo referiré la sustancia de lo que ambos dicen de este religioso». Sigüenza degué consultar l'epístola original que va enviar Pere Coll a Agustí Galbes el 15 d'octubre de 1513 i que ara estem trascrivint per a la tesi doctoral. Es conserva a la Biblioteca d'El Escorial al manúscrit \&-II-22 (235r-236v).

9 ACV. Ms 368, cap. 34, p. 224. També al manuscrit de la Biblioteca d’El Escorial \&-II-22 (235r-236v).

SCRIPTA, Revista internacional de literatura i cultura medieval i moderna, núm. 16 / desembre 2020 / pp. 215-222 ISSN: 2340-4841 · doi:10.7203/SCRIPTA.16.19226 
Enderezando la plática a la moza, le fue preguntando de esta manera: «¿Vos, hija, sois cristiana?», respondió que sí. «¿Sabéis el Credo y aveis os confesado este año?», sí respondió la moza. "¿Y creéis que nuestro Señor, Jesucristo, que os crió y os ha redimido con su preciosa sangre, os puede sanar?». «Sí creo», respondió la moza.

I després d'haver comprovat que era tan devota com bona cristiana va tornar a obrar el miracle:

\begin{abstract}
Entonces tomole la una mano y fregósela con la suya, y lo mismo el brazo. Y al punto se halló tan sana y libre como si en toda su vida no hubiese padecido mal alguno. Tomole luego la otra mano y le dijo: «¿Vos, hija, creéis que las cosas que Dios hace, las hace cumplidas y perfectas, y que como os ha dado salud en la una mano os la puede dar en la otra?». Respondió: «sí creo, padre». Entonces le fregó la otra mano y el brazo con la suya, y al punto quedó tan sana como la otra.
\end{abstract}

Com s'ha vist fins ací, el miracle de la fe cristiana i de la gent que hi creu podia més que la ciència d'un metge jueu, segons els fets reportats per Francesc Castillo.

El tercer dels monjos jerònims de Cotalba no obra miracles ni és jueu convers. Però sí que prové d'un dels llinatges històrics del regne de València, dels Valeriola. Jerònim Valeriola, diu el cronista ${ }^{10}$ va prendre l'hàbit i va professar el 1534 i 1535, respectivament. És un personatge clau en les corts del Regne i un dels pocs frares de Cotalba que es va immiscir en la política del seu moment. De fet, Pere Maria Orts (1971) va dedicar-li un estudi i el mateix historiador de l'Orde, José Sigüenza (1909: 190-199), va fer-ne una extensa biografia, que és la que resumeix Francesc del Castillo.

El cronista destaca de Valeriola que
salido de la escuela [...] comenzó a notificarse, y a cercenar de la comida y del sueño, de suerte que se admiraban todos de ver como podía pasar con tan poco como comía. Y del sueño vino a acostumbrarse a no dormir sino sola una hora entre noche y día, y aseguraba que con aquella hora quedaba tan satisfecho como si hubiera dormido toda la noche.

Però aquell costum de no menjar i dormir poc provocà a Valeriola alguns problemes de salut: «De resulta de estas y otras penitencias vino a echar sangre por la boca de cuyo accidente no hizo mucho caso y después sanó».

Que era intel ligent i culte ho demostra que estudiara gramàtica, filosofía, teologia escolàstica i les llengües grega i hebrea. En virtud de la seua intel ligència i capacitat de gestió, el van nomenar tres vegades prior de Cotalba. Diu Castillo que «estaba a veces tan abstraído y transportado en su silla, que algunas veces era preciso tirarle del escapulario para que acordade algunas cosas en que no reparaba por abstraído». Sembla que la falta de son li passava factura.

10 ACV. Ms 368, cap. 34, p. 231-232. 


\section{Rubén Galera. Vides i successos de quatre monjos de Sant Jeroni de Cotalba}

Una altra vegada, «predicando una Cuaresma en Barcelona y teniendo sermón todos los días, en toda la Cuaresma no durmió más de 40 horas. Una cada día. En aquest sentit se’l recorda perquè algunes vegades

le vieron trasportado y sin sentido con los ojos abiertos. Y sin ver ni oir [...] Otra vez estuvo inmóvil y sin sentido desde que acabó de decir misa hasta la tarde, a tiempo que querían tocar vísperas sin ningún uso de los sentidos.

Com veiem, va ser un monjo virtuós per la seua capacitat d'abstindre's de la realitat que l'envoltava, si no és que fora realment lagoftàlmic; és a dir, que poguera dormir amb els ulls oberts.

L'últim dels frares que citarem no va ser un virtuós ni va obrar cap miracle. Simplement es va salvar de ser segrestat en un succés anecdòtic. Francesc Berenguer ${ }^{11}$ també provenia, com Jerònim Valeriola, de família de bona cuna, «de aquel insigne general Berenguer de Entenza que tanto se señaló con la conquista de este reino en tiempo del rey don Jaime el Conquistador». En opinió de l'historiadors de l'Orde, «fue de una vida inculpable, penitente, devoto, obstinente, humilde, obediente, sufrido, casto y, sobre todo, hallaba sus delicias en asistir y ayudar en el Santo Sacrificio de la misa». Sobretot en la missa és on millor exercia la seua devoció.

Sembla que no va tindre un ofici fixe en el si del monestir, per la qual cosa feia faenes d'obrer, d'ortolà i de llaurador, entre altres labors. Però en totes, segons remarca Castillo, «todo lo hacía bien, por lo que nunca le dejaban parar». A causa de la seua versalitat en les tasques monàstiques:

\footnotetext{
Mandáronle un tiempo que guardase unas cabras que tenía el convento. Obedeció gustoso, pero como le era preciso mantenerse todo el día y aun muchas noches por aquellas sierras de que está rodeada esta casa, le era muy gravoso no poder oir y ayudar las misas a que tenían tanta devoción.
}

I eixe era l'aspiració del dissortat monjo: oir i participar en les misses diàries; i en contrapartida havia d'exposar-se als perills de la vida mundanal que tant espaordien els monjos, segons les versions filtrades de les cròniques de l'Orde.

Segueix el cronista i fa un breu apunt contextual:

Era esto a tiempo que todo este reyno estaba aun lleno de moriscos y moros muchos de ellos fingidamente conversos, que ocultamente tenían con los de África ordinarias correspondencias, por lo cual venían muy ordinario piratas de Berbería de noche para cautivar cristianos ayudados de los moros naturales.

11 ACV. Ms 368, cap. 34, p. 252-255. 
Per tant, ja podem imaginar-nos al perill a què podia exposar-se fra Francesc Berenguer, prop de la costa saforenca, en la qual encara no hi havia torres de guaita. Diu el cronista que:

Como no había entonces torres que guardasen esta costa como ahora, desembarcaron los moros y llegaron a un monte cerca del monasterio, en donde fray Berenguer guardaba su ganado. Arremetieron el buen pastor, furiosos, para llevársele.

Però sortosament, seguisc amb la crònica,

\begin{abstract}
a tiempo que se cantaba en el convento la misa conventual, y al santus es costumbre se den nueve golpes sin interrupción con la campana grande, con lo cual oyendo los moros se persuadieron que tocaban a arrebato. Y temiendo no les cogiesen la parte del mar y quedasen esclavos, huyeron presurosos a tomar su embarcación, y así permitió nuestro Señor por mucha devoción que este siervo había tenido a la misa, que por la misa se librase de aquel peligro.
\end{abstract}

\title{
4. Acabament
}

A pesar del nombre elevat de vides que contenen les cròniques jerònimes, ací la de Cotalba, no sempre ens resulten interessants perquè no contenen fets especialment rellevants. La majoria parlen de les qualitats dels bons religiosos en la seua fe, que si ho veiem en perspectiva té sentit perquè els ordes monàstics vivien al segle XVIII un cert relaxament moral. Hem llegit en altres documents que estem treballant, que a Cotalba es feien partides de pilota valenciana i travesses, o siga, apostes. I d'això, a les cròniques oficials no se'n diu res. Espere que els resultats de la tesi en què ens hem embarcat i la documentació que vaig arreplegant a mesura que hi avance, ens aporte més informació de les vertaderes vides secretes, si es pot dir així, d'un dels centres espirituals més influents del Regne de València a llarg del temps. 
Rubén Galera. Vides i successos de quatre monjos de Sant Jeroni de Cotalba

\section{Bibliografia}

Chabàs, R., 1886, «El rey Felipe II en el Real Monasterio de San Gerónimo de Gandía, antes de Cotalva, por el padre fray Francisco Castillo», El Archivo, any 1, núm 10, 8 de juliol de 1886, p. 74-77.

Orts, P. M., «Regalismo en el siglo XVI: sus implicaciones políticas en la Diputación de Valencia», Primer Congreso de Historia del País Valenciano : celebrado en Valencia del 14 al 18 de abril de 1971, 1971, p. 219-226.

Sigüenza, J., 1907-1909, Historia de la Orden de San Jerónimo, Imprenta Real, Madrid, Tom II.

SCRIPTA, Revista internacional de literatura i cultura medieval i moderna, núm. 16 / desembre 2020 / pp. 215-222 ISSN: 2340-4841 · doi:10.7203/SCRIPTA.16.19226 